\title{
Effects of Land Cover Changes to the Quantity of Water Supply and Hydrologic Cycle using Water Balance Models
}

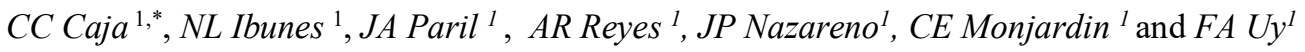 \\ ${ }^{1}$ School of Civil, Environmental and Geological Engineering, Mapúa University 658 Muralla St., Intramuros, Manila \\ 1002, Philippines
}

\begin{abstract}
The hydrologic cycle is a recurring consequence of different forms of movement of water and changes of its physical state on a given area of the earth. The land cover of a certain area is a significant factor affecting the watershed hydrology. This also affects the quantity of water supply within the watershed. This study assessed the impacts of the changing land cover of the Ipo watershed, a part of the Angat-Ipo-La Mesa water system which is the main source of Metro Manila's water supply. The environmental impacts were assessed using the interaction of vegetation cover changes and the output flow rates in Ipo watershed. Using hydrologic modelling system, the hydrological balance using rainfall, vegetation and terrain data of the watershed was simulated. Over the years, there has been a decreasing land cover within the watershed caused mostly by deforestation and other human activities. This significant change in the land cover resulted to extreme increase in water discharge at all streams and rivers in the watershed and the water balance of the area were affected as saturation and shape of the land terrain changes.
\end{abstract}

\section{Introduction}

Water is a very important element in the earth. It comprises about $70 \%$ of the earth's surface and it is very easy to find. But then, people can intake only $2.5 \%$ of these waters, which is freshwater. Metro Manila gets it share of water supply from the Angat-Ipo-La Mesa system and the Laguna De Bay. But these sources does not only provide water but also is used for irrigation, hydroelectric power supply and for flood control. These purposes show the importance of water to the lives of people in the metro and also for nearby provinces [7].

The Ipo watershed is a mountain reserve that values the inhabitants in the area. It is bounded and secluded by proclamation no. 391 from the total horizon of the Angat watershed. But to sum it all up, it is part of a water system that extends from Angat-Ipo-La Mesa [7]. For the past countless months, there have been major concerns of deforestation. Illegal logging, Slash and Burn Farming or 'Kaingin', and charcoal making were major forest disruptions in the area. This causes an alteration to the vegetation in the area. Vegetation plays an important role in the infiltration and runoff in the soil. Changes in the vegetation cover from woodland to agricultural land lowers the infiltration rate of the soil. This may be one of the causes of the alteration and disruption of the hydrological cycle in the area. Thus, leading to a more major concern of decrease in water level in the Angat-Ipo Watershed.
In recent years, many studies have been conducted to assess the impact of land use changes to the hydrological cycle of an area. However, the effects vary from place to place due to their geographical varieties [1-6].

During the previous decade there have been two situations where the Angat Dam, that it is directly connected to Ipo Dam, dipped below minimum operating levels. First was in 2010 where it reached a low record of 157.56 meter above sea level (masl), which was when the Philippines experienced El Niño. Second one was this summer season of 2014 where it reached 162.74 masl.

The study evaluates the water balance in the Ipo watershed with respect to the scenario of land cover changes in the area. The group will present the study by correlating the water balance and the hydrological response in the Ipo watershed throughout the different scenarios of land cover for the past years. Specifically, it sought answers to the following questions which are

1. What are the environmental impacts of changing land cover to the Ipo watershed?

2. How does changes in the land cover of Ipo Watershed affect the following hydrological cycle and the quantity of the water supply

This study addresses the effects of varying vegetation cover to the water balance of the watershed. The study will be of utmost importance to hydrologists, foresters, civil engineers and water-related practitioners which is of concern to the status of water storage in the Angat-Ipo watershed. The analysis and results to be done from the

\footnotetext{
* Corresponding author: chennieccaja@gmail.com
} 
study will further enhance the understanding of our experts in the maintenance of the dam and its surrounding watersheds.

This paper may be used as a reference for future studies. This will help the concerned government agencies to analyze the water balance of the Ipo dam and hence, make ways of preventing water crises in the future. This could also educate our people about the diverse effects of deforestation in our everyday living. In general, this study will benefit the entire community.

\section{Methodology}

This study is conducted based on the framework shown in Figure 1. In preparation for the study, there are basically 3 important data to be gathered. The Digital Elevation Model (DEM) data, Land cover Map, and the Precipitation Gauge data. This will include the conceptual modeling of the domain of the study in ArcGIS. The ArcGIS software is a geographical information system that compiles geographic data and analyzes mapped information that will allow the study to assess and manage the study area.

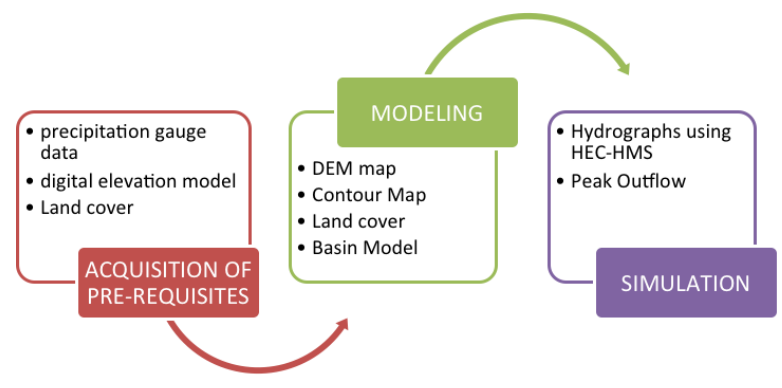

Fig. 1. Conceptual Framework

For the simulation procedure, the study is to use Hydrological Engineering Center - Hydrologic Modeling System (HEC-HMS) software. It is to be modeled in a mathematical condition where there are changing hydrometeorological conditions using set of equations that represent the response of the hydrologic components. It will be a continuous model where in it is simulated at a longer period predicting watershed response with response to the scenarios of precipitation.

This will include different model components namely: State Variables, parameters, boundary conditions and initial conditions. State variables is the condition or the state of the watershed at a certain period. Parameters will be the overall control point of the systems input and output. Boundary conditions are the changing parameter which will affect the state of the watershed and will bring a noticeable change to the system input.

The research pattern of the study starts with the model analysis of the research area. Processing the acquired data into different software in ArcGIS and HEC-HMS. For the research we are to process 3 past scenarios of land cover. We are to analyze the results of the simulation and come up with a conclusion on the relevance of land cover with response to the overall water intake in the watershed

The research setting is at Ipo Watershed declared under proclamation no. 391 at the boundaries of Bulacan, Philippines. The watershed is at a total area of 7,700 ha. According to articles, the current situation at ipo dam is at least $70 \%$ of the forest cover of the ipo watershed is gone.

There are 2 basic steps for the study, Modeling and Simulation. Modeling is done with the aid of the ArcGIS software. The DEM data is pre-processed in this software to organize the data's conditions to be used in the simulation. The simulation done in the study will be aided by HEC-HMS software. After organizing the DEM data, it is transferred to the HMS software and added with other supporting data to create a whole simulation of the hydrological cycle in the area. For the study, we are to simulate 3 past years with varying vegetation cover. The process done in the study is to vary the Curve Number of the Model. The curve number represents the vegetation within a specific area to represent its infiltration and other related vegetation parameters.

The land cover maps and the Digital Elevation Model (DEM) of the Ipo watershed were gathered from the National Mapping and Resource Information Authority (NAMRIA). It was then processed using a GIS software. Figure 2 shows the location map of the Ipo watershed $[8,9]$.

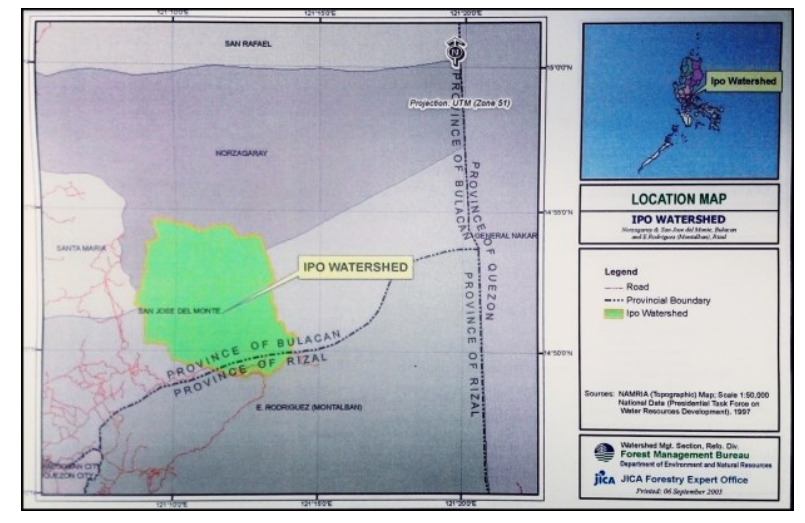

Fig. 2. Location Map (DENR-FMB, 2005)

After the Model analysis of the watershed, the water balance in the watershed is to be simulated in the HECHMS software. The different parameters in the watershed is to be input and to be analyzed and processed in the software to create an overall hydrological simulation and water balance in the watershed.

\section{Results and Discussion}

\subsection{Terrain Assessment}

The watershed was processed in the ArcGIS and can be seen through different viewpoints. One is by processing its image classification and processing it to view the Landcover. Another is by processing it with different parameters under the GeoHMS toolbar and processing 
the land area as sub basins to be used in the HMS software. For the image classification, it is classified under each category of land cover and is differentiated by color to identify different types of land cover. The sub watersheds are divided and classed under different vegetation types defined by different shades of color as seen in Figure 3. For the year 2003, most of the area are seen to be closed forest. But, as several years had passed, most then are now classified under wooded grasslands. These shows that there are major disruptions in the land cover in the area.
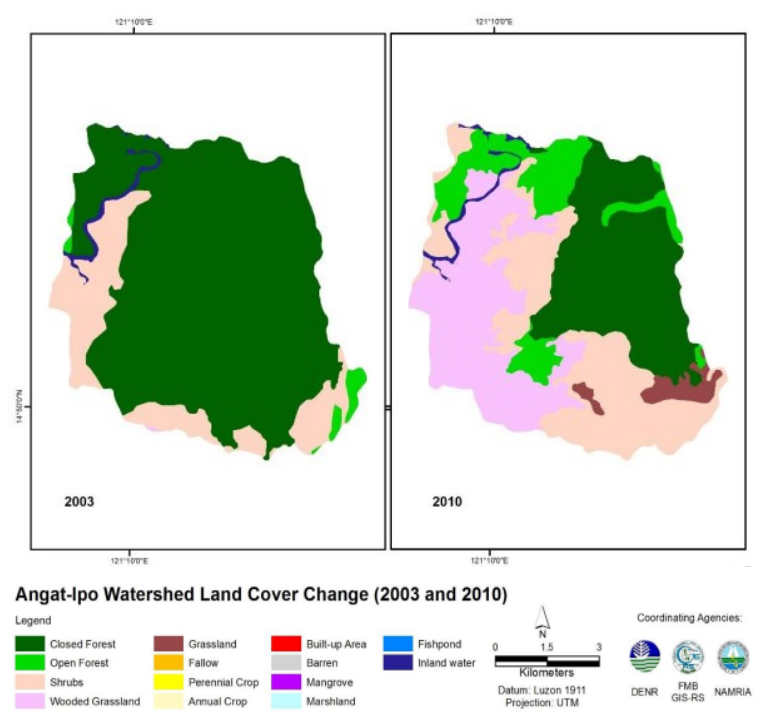

Fig. 3. Land cover change of Angat-Ipo watershed, 2003-2010

As processed, the eastern side of the watershed has been kept solid into a closed forest, but most of the western part of the watershed has been turned into a combination of shrubs and wooden grasslands. This shows an entirely different variation in the perspective of land cover for the watershed.

Each type of vegetation corresponds a certain curve number to indicate flow infiltration and surface runoff. Table II shows the corresponding curve number for each land cover type.

Table 1. Criteria for Curve number.

\begin{tabular}{|c|c|}
\hline Land Cover type & Curve number \\
\hline Closed forest & 77 \\
\hline Shrubs & 78 \\
\hline Open forest & 79 \\
\hline Wooden grassland & 82 \\
\hline Grassland & 84 \\
\hline Forage & 89 \\
\hline
\end{tabular}

\subsection{Modelling and Simulation}

A hydrologic modelling software was used for the simulation of the model for the different years. The Figure 4 shows the Ipo watershed and its sub basins processed in the software. The different parameters, such as Curve number, were used as input to be analysed and processed in the software to create an overall hydrologic simulation and water balance in the watershed. The hydrographs produced were assessed to study the area's forecast flow, water availability and impacts of sudden changes in the environment.

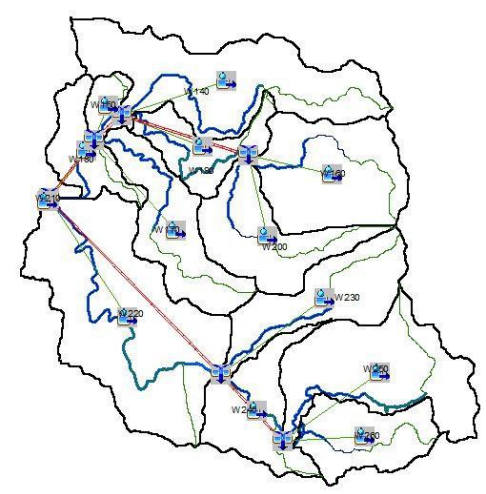

Fig. 4. Ipo watershed and sub basins

After getting the unit hydrograph, a convolution of the unit hydrographs with the precipitation ecess was computed and the runoff for a specific time frame was determined. These hydrographs, once processed into convolution, produced total volume runoffs, and so the flow of the water in the reservoir was determined, predicting how much water is present in the system. Doing the same process for the different year, the overall water balance in the system with respect to the changing years and varying vegetation cover in the area was compared and analysed.

Figure 5 shows the hydrographs for years 2003, 2010 and 2014. With varying inputs of curve number depending on the land cover and with varying precipitation gauge record, the peak outflows computed are 391.1, 400.2 and 779.5 cubic meters for 2003, 2010 and 2014, respectively.

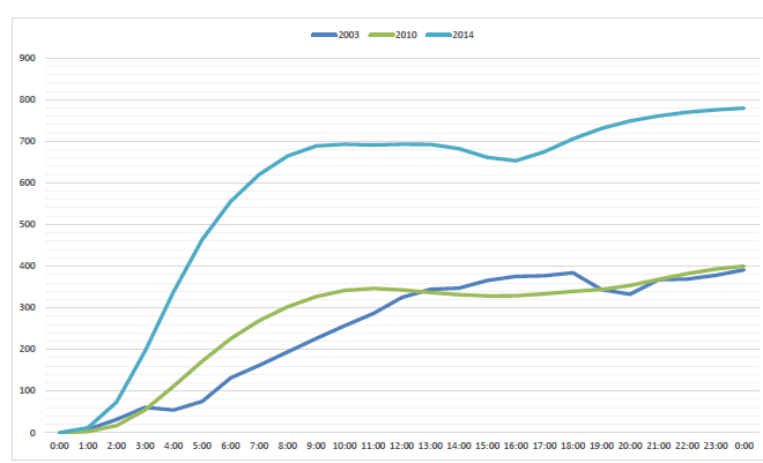

Fig. 5. Time Series Outflow of Ipo Dam 


\section{Conclusion}

This study was conducted to determine the impacts of the varying land cover of the Ipo watershed. It is imminent that with less vegetation in the watershed, rate of infiltration increases. Less forestry and vegetation is a product of deforestation in the area which has been a major problem since the early 2000. With the drastic decrease in number of vegetation, few trees and plants absorb water from the ground, causing the rainwater to directly seep through the soil and find ways to the lower elevations. Thus, the extreme increase in water discharge occurs at nearly all streams and rivers in the watershed including the flow rate measured from the outlet point of the watershed where the Ipo dam is currently situated. The peak flow in 2014 as determined by the study is almost twice of the peak flow computed in the years 2003 and 2010. With this rapidly decreasing land cover in the watershed and the increase in the peak charges, the water balance of the area will be affected as saturation and shape of the land terrain changes. As per the quantity of water supply, the less rate of infiltration provide an increase in water elevation in the Ipo dam, neglecting the water discharge released by the Angat dam.

\section{References}

1. Batra, Yang, Choi, Kumar, Cai, De Fraiture, Understanding Hydrological Cycle Dynamics due to Changing Land Use and Land Cover: A Congo Basin Case Study; University of Illinois, 2008.

2. B.J. Bond, F.C. Meinzer and J.R. Brooks, How Trees Influence the Hydrological Cycle in Forest Ecosystems, John Wiley and Sons, Ltd., 2008.

3. C. D'Almeida, C.J. Vorosmarty, J.A. Marengo, G. Hurtt, S.L. Dingman and B.D. Keim, A Watershed Balance Model to Study the Hydrological Response to Different Scenarios of Deforestation in Amazonia, May 2006.

4. J.M. Roberts, The Role of Forests in the Hydrological Cycle Volume 3, Encyclopedia of Life Support Systems.

5. J. Nemec, Engineering Hydrology, Tata McGrawHill Publishing Ltd., 1964.
6. K.X. Soulis and J.D. Valiantzas; SCS-CN Parameter Determination using Rainfall-Runoff Data in Heterogeneous Watersheds - the Two-CN Approach; Agricultural University of Athens, Department of Natural Resources Management and Agricultural Engineering, Division of Water Resources Management, Athens, Greece, Oct. 5, 2011.

7. Landcover and Digital Elevation Model of the Ipo Watershed; Photogrammetry Division, Mapping and Geodesy Branch, National Mapping and Resource Information Authority, Fort Bonifacio, Taguig City, Philippines.

8. R.C. Pati, Land Cover Changes and Flood Dynamics in the River Basin of Tanay, Rizal, Philippines, July 15, 2014.

9. Terrain Maps of the Ipo Wateshed, Department of Environment and Natural Resources, Forest Management Bureau, Visayas Ave., Diliman, Quezon City, 1100 Philippines. 